\title{
Antirheumatic in SARS-CoV-2: benefit or risk?
}

\author{
Francesco Ferrara \\ Usl Umbria 1, Perugia, Italy
}

\section{Dear Editor,}

About 300 million people worldwide are affected by rheumatic diseases and over 5 and a half million men and women affected by rheumatological diseases are present in Italy. These are chronic diseases and therefore require treatments and diagnostic tests for long periods of time. The needs of these patients must be met even in these difficult months marked by the COVID-19 pandemic. The guarantee of continuity of treatment is important and increasingly dangerous is the lack of many drugs. This deficiency is due to the fact that many antimalarial and anti-inflammatory drugs have entered the protocols for the treatment of people with SARS-CoV-2. Without taking these medicines, which for years have also been used in rheumatology, there is a risk of reactivating serious diseases such as rheumatoid arthritis, ankylosing spondylitis or systemic lupus erythematosus in people who have been under chronic treatment for years.

In addition, there is also another problem: antirheumatic drugs are often associated with viral and bacteriological infectious events that cause high inflammatory states and for this, people treated for arthritis, would have an increased risk of contracting

Correspondence: Francesco Ferrara, Usl Umbria 1, P.le Gambuli, 06132, Perugia, Italy.

E-mail: francesco.ferrara@uslumbria1.it

Key words: SARS-CoV-2; antirheumatic; COVID-19; infection; immunology.

Conflict of interests: the author declares no potential conflict of interests.

Received for publication: 15 April 2020.

Revision received: 28 April 2020.

Accepted for publication: 28 April 2020.

This work is licensed under a Creative Commons Attribution NonCommercial 4.0 License (CC BY-NC 4.0).

${ }^{\circ}$ Copyright: the Author(s), 2020

Licensee PAGEPress, Italy

Italian Journal of Medicine 2020; 14:114-115

doi:10.4081/itjm.2020.1290 the virus. But once the infection is contracted, the immune and anti-inflammatory response mechanisms are activated which serve to eradicate the virus, but they are so intense that become pathological, inducing not only bilateral interstitial pneumonia, but also damage to other areas of the body, as emerges from the autopsies of patients who died of COVID-19. For this reason, immunosuppressive or potent anti-inflammatory drugs that have given important results in other pathologies are used, so it is not difficult to predict that some medicines used in rheumatology could also be commonly used for COVID-19 and are currently being tested. There are two categories: i) drugs that can inhibit viral replication (e.g. chloroquine, hydroxychloroquine); ii) drugs capable of repressing the inflammatory cytokine storm (still chloroquine and hydroxychloroquine, colchicine and the range of biotechnological drugs- tocilizumab, IL-6 inhibitors, anti-IL1 and anti-TNF $\alpha$ - and small molecules (e.g. baricitinib).

At the moment there is no scientific evidence showing a higher risk of coronavirus infection in the case of a rheumatological disease, therefore treatment should not be avoided for fear of possible infections. The administration of immunosuppressant drugs should only be stopped if flu-like symptoms such as fever or cough occur. This is a normal medical practice which must be performed independently of COVID19. As for the start of new immunosuppressive or biological drug therapies, in this critical period for the health system, the choice is up to the rheumatologist. It is preferable to start these treatments, which present an infectious risk, only in cases of certain pathologies that can have strongly negative effects on health or cause damage to vital organs.

The due reflection is that antirheumatic drugs risk represents a paradox: on the one hand they treat people infected with COVID-19, but on the other hand they put at risk the uninfected people making the rheumatic population more vulnerable to the virus with the risk of infecting more people than they those saved with the same drugs. ${ }^{1-15}$ Hence the doubt: if antirheumatic drugs demonstrate efficacy against COVID-19 is it better to suspend them in rheumatic people and use those in the COVID-19 population (with the risk of 
reactivating rheumatic diseases) or shall we continue to treat people with arthritis exposing them to the risk of virus and fueling the ongoing pandemic?

\section{References}

1. World Health Association. Coronavirus disease 2019 (COVID-19) situation; Report - 61; 2020. Available from: https:/www.who.int/docs/default-source/coronaviruse/situation-reports/20200322-sitrep-62-covid19.pdf Accessed: 22 March 2020.

2. Xu Z, Shi L, Wang Y, et al. Pathological findings of COVID-19 associated with acute res-piratory distress syndrome. Lancet Respir Med 2020 [Epub ahead of print].

3. Huang C, Wang Y, Li X, et al. Clinical features of patients infected with 2019 novel coro-navirus in Wuhan, China. Lancet 2020;395:497-506.

4. Zou L, Ruan F, Huang M, et al. SARS-CoV-2 viral load in upper respiratory specimens of infected patients. $\mathrm{N}$ Engl J Med 2020 [Epub ahead of print].

5. Nicastri E, Petrosillo N, Ippolito G, et al. National Institute for the Infectious Diseases "L. Spallanzani" IRCCS. Recommendations for COVID19 clinical management. Infect Dis Rep 2020;12:8543

6. World Health Organization. Clinical management of severe acute respiratory infection (SA-RI) when COVID19 disease is suspected: interim guidance; 13 March 2020. Available from: https://apps.who.int/iris/bitstream/handle/10665/331446/WHO-2019-nCoV-clinical-2020.4-eng.pdf Accessed: 22 March 2020.

7. Liu J, Cao R, Xu M, et al. Hydroxychloroquine, a less toxic derivative of chloroquine, is efective in inhibiting SARS-CoV-2 infection in vitro. Cell Discov 2020;6:1-4.

8. Schrezenmeier E, Dörner T. Mechanisms of action of hydroxychloroquine and chloroquine: implications for rheumatology. Nat Rev Rheumatol 2020;16:155-66.

9. Rolain JM, Colson P, Raoult D. Recycling of chloroquine and its hydroxyl analogue to face bacterial, fungal and viral infections in the 21 st century. Int J Antimicrob Agents 2007;30:297-308.

10. Gao J, Tian Z, Yang X. Breakthrough: Chloroquine phosphate has shown apparent efcacy in treatment of COVID-19 associated pneumonia in clinical studies. Biosci Trends 2020;14:72-73.

11. Gautret P, Lagier JC, Parola P, et al. Hydroxychloroquine and azithromycin as a treatment of COVID-19: results of an open-label non-randomized clinical trial. Int J Antimicrob Agents 2020 [Epub ahead of print].

12. Chang R, Sun WZ. Repositioning chloroquine as ideal antiviral prophylactic against COVID-19-time is now; 2020. Preprints available from: https://doi.org/10.20944/ preprints202003.0279.v1

13. Ruan Q, Yang K, Wang W, et al. Clinical predictors of mortality due to COVID-19 based on an analysis of data of 150 patients from Wuhan, China. Intensive Care Med 2020 [Epub ahead of print].

14. Mehta P, McAuley DF, Brown M, et al. COVID-19: consider cytokine storm syndromes and immunosuppression. Lancet 2020 [Epub ahead of print].

15. Chen X, Zhao B, Qu Y, et al. Detectable serum SARSCoV-2 viral load (RNAaemia) is closely associated with drastically elevated interleukin 6 (IL-6) level in critically ill COVID-19 patients; 2020. Preprints available from: https://doi.org/10.1101/2020.02.29.20029520 